\title{
The Research and its Significance of the Sedimentary Facies Feature of the KBM Oilfield East Area
}

\author{
Feng Youkui \\ School of Energy Resources, China Geology University, Beijing 100083 \\ email: fyk815@163.com
}

Keywords: sedimentary facies belt; identification mark of sedimentary facies; delta; oil-water-relation Abstract. The complex oil-water relation of study area related to sedimentary facies. But the unconformity resulted from frequent tectonic movements puzzled the study of sedimentary facies. Based on the detailed study on the cored wells, the main identification marks of sedimentary facies have been analyzed via core observation, logging analysis, core testing and etc. The result shows that the Eastern Area of KBM Oilfield was littoral shallow sea delta facies, and developed three subfacies: delta plain, delta front and shallow sea. Further study on sedimentary microfacies features and distribution revealed the internal relationship between oil-water-relation and sedimentary facies belt. It provides basis for boundary expanding evaluation and development adjustment.

\section{Introduction}

Several studies have been made upon $\operatorname{KBM}$ Oilfield $[1,2,3]$, but historically there were little information on geology while former studies mainly focused on aspects of structure and reservoir in this oilfield [4-6]. Via studies on the sealed coring data in the new drills of East Area, for the first time this paper systematically studied on the identification of sedimentary facies marks, behavior and distribution regularities of sedimentary facies in the East Area of KBM Oilfield. Detailed studies on sedimentary microfacies lead to better identification and prediction of reservoir behavior and clarification of oil-water-relation.

\section{The Oilfield Overview}

The KBM Oilfield is located in the north-west of Buzachi Peninsula, SW Coast of the Republic of Kazakhstan, next to the eastern coast of Caspian Sea. It is structurally located in the North Buzachi Uplift of Ustyurt Basin (Figure 1).
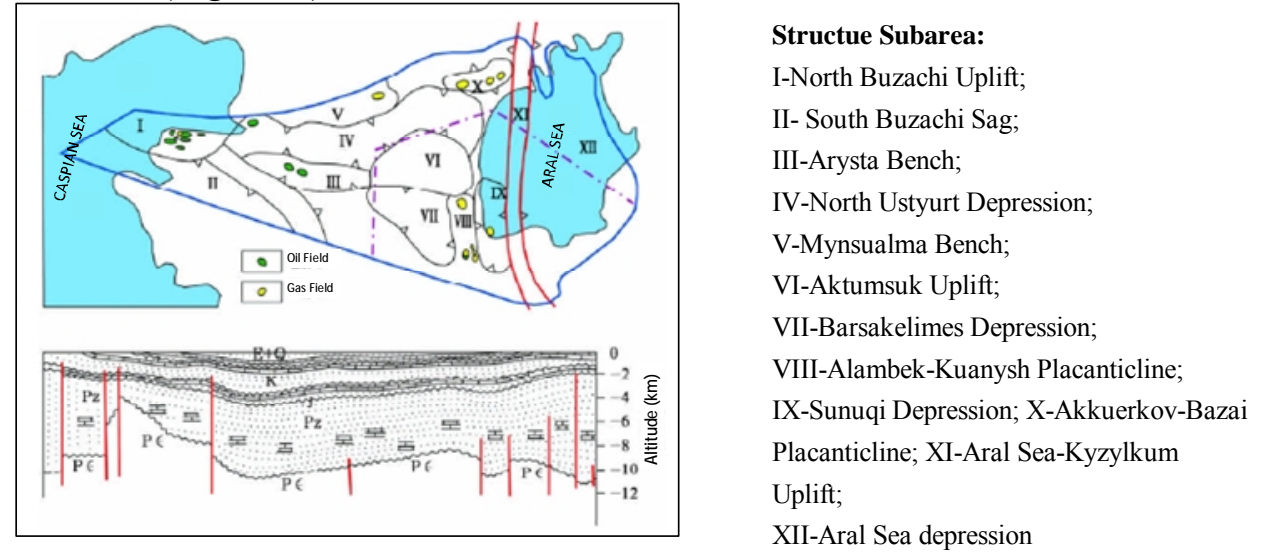

XII-Aral Sea depression

Chart 1 The plan and profile of North Usturt Basin

The oilfield was discovered in 1974 with a proven reserve of 300 million tons hydrocarbon. It is an anticline-type heavy oil reservoir and its main oil-bearing strata series includes Middle Jurassic and Lower Cretaceous sandstones. The oil-bearing strata is divided into several development horizons: A, B, V, G, D, J1, J2, among which, Horizon A, B, V, G, D are located in the lower Cretaceous reservoirs and $\mathrm{J} 1, \mathrm{~J} 2$ are in the Mid Jurassic reservoirs(Figure 2). 


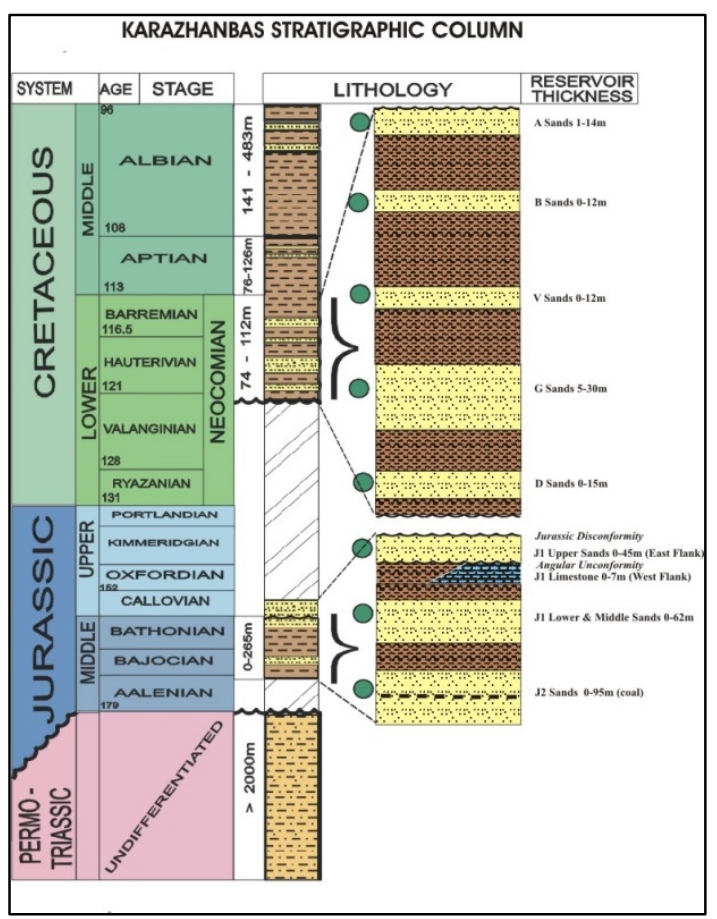

Chart 2 Oilfield Layer Columnar Section

\section{Sedimentary Behaviors and Distribution Regularities}

At the End of Triassic, the area was overall uplifted and then suffered regional erosion. The Jurassic strata had an early-stage stratigraphic gap. The upper-mid Jurassic had a sedimentary behavior of shallow water transition zone under a water regression. The Cretaceous was deposited under a multi-stage water transgression and regression after the uplift and erosion in the late Jurassic.

\section{Major Facies Marks Behaviors}

Facies Marks are mostly analyzed by mineral composition marks, fabric marks, deposit structure marks, geophysics and geochemistry marks, paleontological fossil marks and so on ${ }^{[7]}$. To identify the sedimentary facies of the area, based on data analysis of core, well logs and laboratory test, the study is to determine the major identification marks of the Jurassic and Cretaceous sedimentary facies in the area.

\section{Mineral Composition Marks}

Based on the core data, the Jurassic reservoir is mainly fine sandstone, interbedded siltstone, mudstone and thin coal bed; the Cretaceous reservoir is mainly fine sandstone, siltstone, unequally thickness interbedding of argillaceous siltstone and mudstone (mudstone accounted for the larger proportion of the formation than that of sandstone). It is stated that the sediments have experienced a long-distance transportation and the provenance is far. Mudstones are dark gray, light gray, grayish-green and brown red could be visible on part of the samples, which indicates that the deposition mainly occurred in reduction environment but some also in oxidation environment(Figure 3-a).

Via optical microscope, SEM and XRD analysis, $\mathrm{K}$ feldspar is commonly visible in the detrital grains, while K feldspar hyperplasia could be seen in some samples (Figure 3-b). The clay minerals are dominated by illite -smectite; in authigenic minerals, chlorite and pyrite are commonly visible, acting as the pore lining / pore filling (Figure 3-b). 


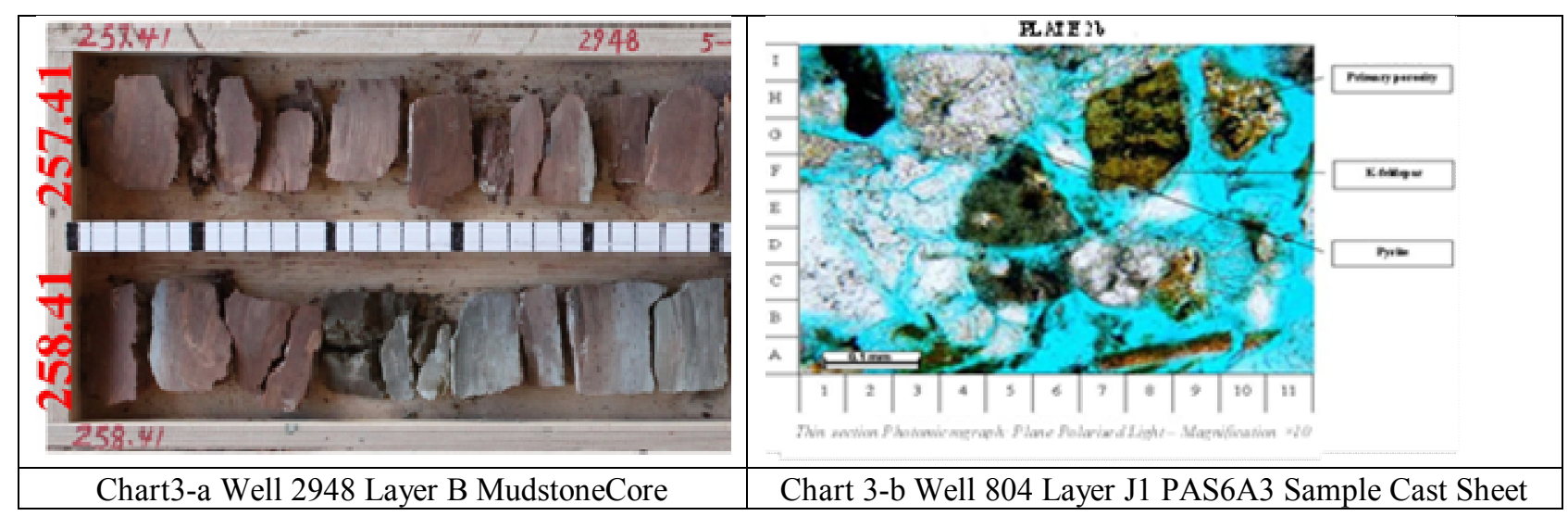

\section{Fabric Marks}

As a significant mark for sedimentary facies identification, in the study area, a large number of samples have the probability cumulative curves of grain size which reflect the traction curve characteristic, collating the standard curve of G.S.Visher $(1969)^{[8]}$. The curve shapes are up-convex arc with mostly three segments and a few with two segments. In the C-M diagram PQ and QR are mainly developed, which indicates that the particles are fine granularity, dominated by suspension and saltation. It indicates that the geological stress is weak and the fluid is traction current (Figure 4-a). Based on the calculation result of Sahu discriminant formula, analysis indicates fluvial or delta depositional system(Figure 4-b).

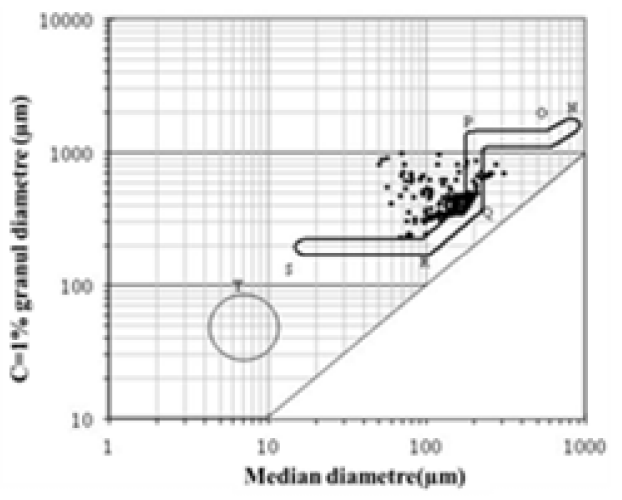

Chart 4-a KBM Oilfield East area C-M Chart

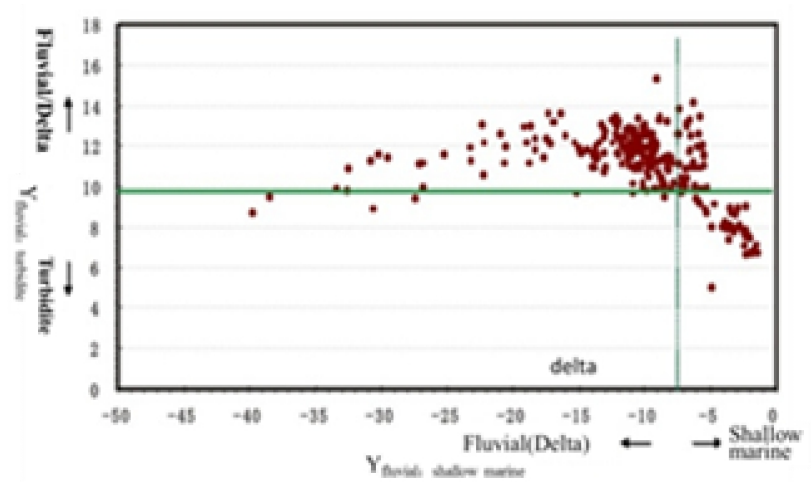

Chart 4-b Sahu Distinguish Formula Intersection Chart

\section{Deposit Structure Marks}

As the Rock has a loose cementation and some is dipped by heavy crude oil, deposit structure in some part of the coring section is not obvious. But, through comparative observation of systematic coring well, it is discovered that the major deposit structures are parallel bedding (Figure 5-a), cross bedding, linear inclined bedding, lens and falser bedding (Figure 5-b), wavy bedding (Figure 5-c), horizontal bedding seen in mudstone and so on.

Scour-fill structure is commonly developed at the bottom of sand body, mud gravel is also commonly seen(Figure 5-d), which is a significant symbol of fluvial deposition, indicating that the sedimentary environment had a weak energy at that time and it was affected by fluvial and wave, two kind of forces. 


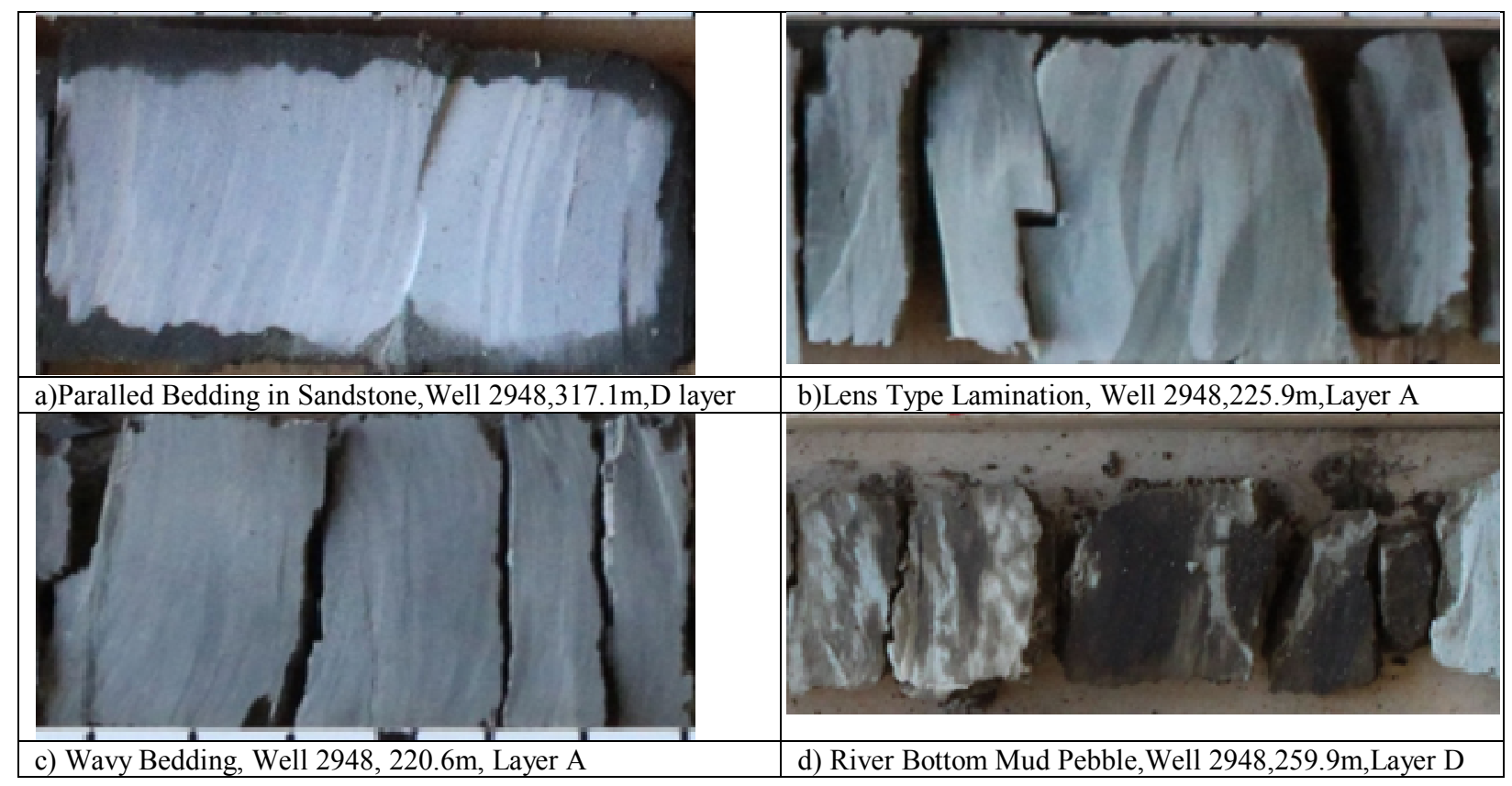

Chart 5 KBM Oilfield East Area Sedimentary Structure Mark

\section{Paleontological Fossil Marks}

The Jurassic formation is rich in plant debris, plant roots, carbonaceous lamina, and thin coal layer, reflecting the warm and humid climate. The Cretaceous mudstone developments organism burrows and biological tectonic disturbance, indicating that the water was becoming deeper in the Jurassic period, but it is above the wave base plane. Additionally, based on 55 analysis results of SEM and XRD within 3 wells in the area, $\mathrm{K}$ feldspar hyperplasia is commonly visible; chlorite grain is commonly developed in authigenic minerals; brachiopod ostracum is slightly seen in sample S53, Well 4985(Figure 6). The brachiopod has parallel-wavy thin-layer shell structure which roughly parallel to the edge of the shell (Figure 6), indicating shallow sea environment.

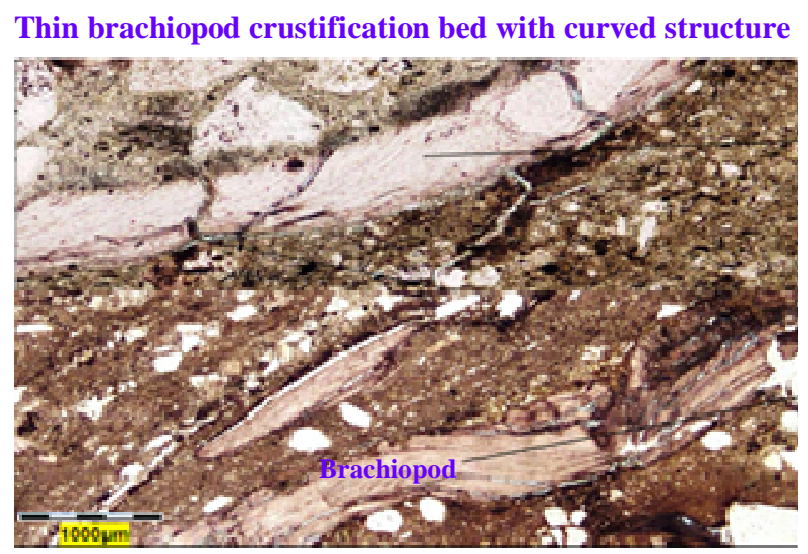

Chart 6 Well 4985 Thin-section Micrograph

(Layer G, Plug 53, Core Depth 312.62m )

In conclusion of identification marks above, combining regional sedimentary background, the author considers that the target strata in the study area belong to littoral shallow sea delta facies deposition.

\section{Sedimentary Facies Type}

Based on single-well facies dividing on the coring well, the result shows that the Jurassic is delta plain subfacies deposition; the Cretaceous is delta front subfacies deposition. Delta plain subfacies deposition can subdivision into distributary channel, interdistributary bay, shore swamp microfacies; delta front subfacies deposition can subdivided into distributary channel, interdistributary bay, estuary bar and distal bar; shallow sea subfacies into shallow sea bar and shallow sea mud microfacies. 
Based on single-well microfacies and profile facies study, according to the rock sorting, sedimentary structure, rhythm, fossils, rock ratio, particle size ,electrical characteristics etc. , basis of plane sedimentary microfacies dividing in the East Area, KBM Oilfield is summarized (Table 1).

Table 1. Criteria for micro-facies classification in the eastern area of KBM oilfield

\begin{tabular}{|c|c|c|c|c|c|c|c|c|}
\hline Criteria & $\begin{array}{l}\text { Distributary } \\
\text { channels }\end{array}$ & Mouth bar & Tributary bar & Distal bar & Front sand sheet & Shallow bay & Swamp & Sea mudstone \\
\hline Sorting & Good & Medium & & Good & Good-Medium & Good & & \\
\hline $\begin{array}{l}\text { Sedimentary } \\
\text { structure }\end{array}$ & scour & $\begin{array}{l}\text { wave-ripple } \\
\text { bedding }\end{array}$ & Parallel bedding & $\begin{array}{c}\text { Wave } \\
\text { crossing bed }\end{array}$ & $\begin{array}{l}\text { avy-looking } \\
\text { crossing bedding }\end{array}$ & $\begin{array}{l}\text { wavy-looking } \\
\text { crossing } \\
\text { bedding }\end{array}$ & Parallel bedding & Parallel bedding \\
\hline Sycles & normal & reverse & & reverse & $\begin{array}{c}\text { Reverse, } \\
\text { combination }\end{array}$ & reverse & & \\
\hline Permeability & High & Medium-Low & & Low & Medium & High & & \\
\hline Fossils & plant stem, leaves & plant leaves & $\begin{array}{l}\text { Bioglyph, } \\
\text { benthos }\end{array}$ & & & & $\begin{array}{l}\text { coalification } \\
\text { fossil }\end{array}$ & Bioglyph, benthos \\
\hline Transport & $\begin{array}{c}\text { leaping } \\
\text { components }\end{array}$ & \begin{tabular}{|c|}
$\begin{array}{c}\text { Leaping, floating } \\
\text { components }\end{array}$ \\
\end{tabular} & $\begin{array}{c}\text { Floating } \\
\text { components }\end{array}$ & \begin{tabular}{c|} 
Floating \\
components
\end{tabular} & $\begin{array}{c}\text { Leaping, Floating } \\
\text { components }\end{array}$ & $\begin{array}{c}\text { Leaping } \\
\text { components }\end{array}$ & $\begin{array}{c}\text { Floating } \\
\text { components }\end{array}$ & $\begin{array}{c}\text { Floating } \\
\text { components }\end{array}$ \\
\hline Lithological ratio & $>40$ & \begin{tabular}{|l|}
$30-40$ \\
\end{tabular} & $<30$ & $30-40$ & $30-40$ & $>40$ & $<30$ & $<30$ \\
\hline $\begin{array}{c}\text { Logging } \\
\text { characteristics }\end{array}$ & $\begin{array}{c}\text { GR-box like, } \\
\text { bell-shaped; } \\
\text { RT-bell-shaped, } \\
\text { milkiness }\end{array}$ & $\begin{array}{l}\text { GR-funnel- } \\
\text { shaped }\end{array}$ & $\begin{array}{l}\text { GR-high value } \\
\text { small dentate; } \\
\text { RT-low value } \\
\text { flate straight }\end{array}$ & $\begin{array}{l}\text { GR-dentate, } \\
\text { DEN- finger } \\
\text { like }\end{array}$ & $\begin{array}{c}\text { GR-dentate, } \\
\text { DEN- finger like }\end{array}$ & $\begin{array}{l}\text { GR-boxing } \\
\text { like, bell like }\end{array}$ & $\begin{array}{c}\text { GR-low value } \\
\text { finger like; DEN- } \\
\text { low value finger } \\
\text { like }\end{array}$ & $\begin{array}{l}\text { GR-high value } \\
\text { dentate;RT-low } \\
\text { value straight }\end{array}$ \\
\hline Grains size & Two section & Three sections & & Two section & Three sections & Three sections & & \\
\hline Others & & & $\begin{array}{l}\text { Bioturbation } \\
\text { fabric }\end{array}$ & & & $\begin{array}{c}\text { Oolite, } \\
\text { intraclast }\end{array}$ & & $\begin{array}{l}\text { Bioturbation } \\
\text { fabric }\end{array}$ \\
\hline
\end{tabular}

\section{Plane Facies Features}

According to the basis of plane sedimentary microfacies dividing, microfacies of each development layer are divided:

J1 layer developed distributary channel and interdistributary bay two microfacies during the deposition. The distributary channel is mainly distributed in the northeast and central region, toward the northeast-southwest or south-north; the interdistributary bay is widely developed in the west, but also in east and center (Figure 7A).

During D layer deposition period, sea-level rose rapidly, the water was deepening, which belonged to the transgression period of delta front facies. Sedimentary microfacies dominated by distributary channel and shallow sea mud. Distributary channel mainly distributed in the north central region, channel, with multi-stage channels overlapped in the vertical, while in the plane it was fan-shaped distribution and accounted for $60 \%$ area of the region. It turned into shallow sea mud toward the surrounding facies (Figure 7B).

During $G$ layer deposition period, sea-level fell and the water turned shallow. There were distributary channel, tributary bay and estuary bar three microfacies. Distributary channel in the study area was contiguous distribution, toward the northeast-Southwest or south-north, which accounted for $70 \%$ area of the region; interdistributary bay in the study area had a extensive development in the south, and also developed in north and central region; the estuary bar developed in the end of the distributary channel in the east(Figure 7C).

During V layer deposition period, the transgression started again and the water gradually became deeper. Shallow sea mud deposition is widely developed, secondly distributary channel. Frontal sand sheet, tributary bay, estuary bar, distal bar, and shallow sea bar was only developed in a small range locally. Distributary channel is banded in the northeast and west, mainly extending NE-SW, which accounted for $15 \%$ area of the region. Interdistributary bay developed on a small scale between the channels; shallow sea bar mainly developed in the southwest. At the end of the distributary channel in the east developed successively the estuary bar, frontal sheet sand; while the west end successively developed the estuary bar and distal bar(Figure 7D).

During the deposit period of B layer water deepened and research area developed mudstone in the shallow sea, accompanied by the distributary channels, sheet like sandstone in the delta front, tributary bay, and branching mouth bars and distal bar developed only in limited area. The distributary channels are distributed northeast-southwest trending in the northeastern and western part of research area in 
shape of belts, covering 15 percent of whole area. Tributary bay are developed limited area, shallow sea bay in the southwestern part. At the end of channel in the eastern area develop the mouth bar, front sheet sand, while end of that in the western area develop mouth bar and distal bar (Figure 7E).

During A layer deposition, the sea-level decreased first and was then rapidly rising. The water became shallow and then deep. The plane sedimentary microfacies was distributary channel mainly, followed by interdistributary bay and estuary bar. Distributary channel in the region was generally developed with a contiguous distribution. With multi-stage channel overlapped in the vertical, it was mainly extending NE-SW which accounted for $60 \%$ area of the region. Interdistributary bay developed between the channels and distributed sporadically in the plane. At the end of the distributary channel in the center and east, estuary bar was developed, and it was contiguous distribution in the center while distributed sporadically in the east (Figure 7F).

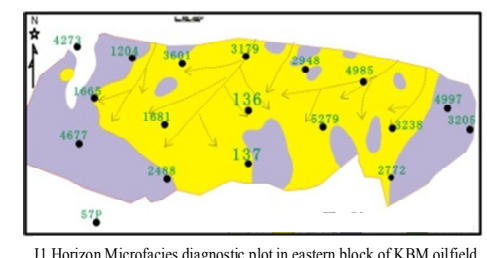

J1 Horizon Microfacies diagnostic plot in eastern block of KBM oilfield

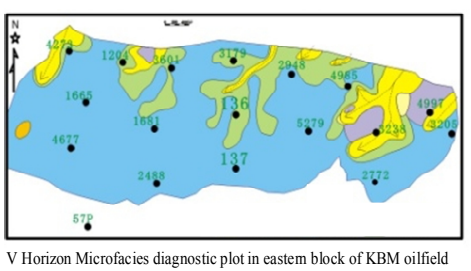

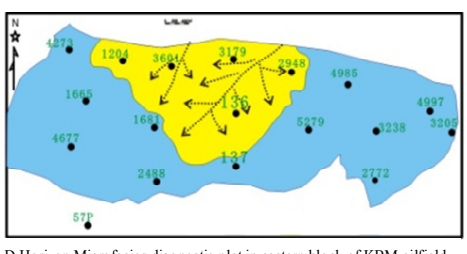
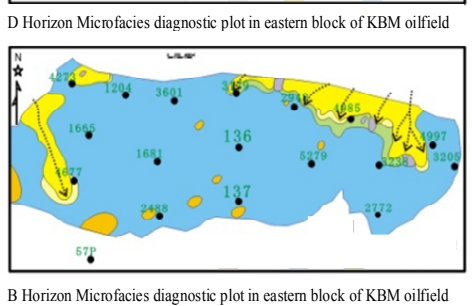
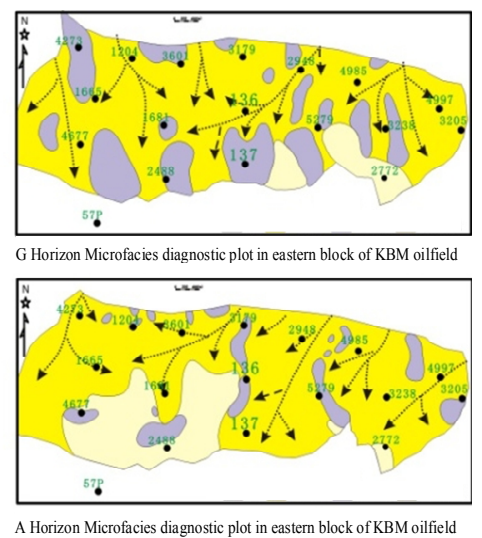

Figure 7. Micro-facies distribution map in the eastern area of KBM oilfield

\section{Conclusion and Significance}

The East Area is the primary oil developing area in KBM Oilfield. Historically, the oilfield lacks basic geology research and has never carried out synthetic studies like sedimentary or reservoir. Confusion exists in the recognition of reservoir development.

Based on the sedimentary microfacies and detailed reservoir research, it is considered that delta plain subfacies and the delta front subfacies are developed widely in the area. Sedimentary microfacies and sand body distribution comparison analysis shows that distributary channel, shallow sea bar, sheet sand and estuary bar microfacies control the region distribution of sand bodies which is favorable facies for oil and gas accumulation. In the area, distributary channel microfacies have the largest distribution area, for it is the optimal zone for oil and gas reservoir.

Sedimentary facies obviously control the reservoir characteristics and distribution of sand body. At the same time, there also could be local storage water formation in the shore swamp associated with coal seams, or, lithological oil and gas reservoir in the shallow sea sand belt. In-depth study of discontinuous rock body is a very good foundation to interpreting the oil-water layer, distinguishing oil-water interface, looking for lithological oil and gas reservoir.

Study on the vertical and horizontal distribution of facies and understanding the reservoir distribution characteristics, establish the foundation for the study of remaining oil distribution in the reservoir during later development, but also provide the basis for new well location deployment and well pattern infilling adjustment. In the exploitation of oil fields, the well network deployment will be arranged based on the distribution of sedimentary facies. The injection-production relationship and intensity will be adjusted according to the various distributions of sedimentary microfacies and sand body $^{[9]}$. 


\section{References}

[1] V.D.Ryabov. Olefins from Karazhanbas Crude Product by in Situ Combustion[J]. Chemistry and Technology of Fuels and Oils Denver. 1996, 32(2):109-113.

[2] Patrick M. Collins. Implementing CHOPS in the Karazhanbas Heavy Oil Field, Kazakhstan[C]. World Heavy Oil congress, Red Hook, NY : Printed by Curran Associates, Inc., 2011, c2008.

[3] V.I.Botova. Paramagnetic Properties of Petroleum Rock of the Karazhanbas Field and Their Change during Thermolysis[J]. Petrol. Chem. U.S.R.R, 1989, 29(3):175-182.

[4] Yixiu Zhu, Wie Zhang. North Usturt Petroliferous Area Oil and Gas geographical Characteristic[J]. Inner Mongolia Petrochemical, 2008, 21: 124-126.

[5] Lidong Zhang. North Ustyurt Basin Structure Evolution and Basic Petroleum Geological Characteristics [J]. Inner Mongolia Petrochemical, 2012, 3: 133 134.

[6] Kai Cui. Kazakhstan AB Oilfield Central Area Oil Reservoir Geological Characteristic and Development Adjusted Technology Study[P]. Zhejiang University Master Degree thesis, 2010, 24-26.

[7] Jianmin Li, Yinping Wu, Xin Ge and etc. The discovery and its meaning of Songliao Basin Saertu Area Neng-1 Section sablacustrine fan [J]. Journal of Oil and Gas Technology, 2012, 34(12): $1-5$.

[8] G.S.Visher. Grain Size Distributions and Depositional Processes [J]. Jour Sed Petrology, vol.39: 1074-1106, 1969.

[9] Zhou Yuan, Ye Tao. Karazhanbas Oilfield Many Times Steam Stimulation Development Effect Influence Factor [J]. Petroleum Geology and Recovery Efficiency, 2010, 17(6): 101-103. 